\title{
Toxemia of Pregnancy in Sheep: a Clinical, Physiological, and Pathological Study
}

\author{
Thomas F. Ferris, Peter B. Herdson, Michael S. Dunnill, and \\ M. RADCLIFFE LEE
}

From the Department of Pathology and the Department of Medicine of the Regius Professor, Oxford University, Oxford, England; the Department of Medicine, Ohio State University, Columbus, Ohio 43210; and the Department of Pathology, Northwestern University, Evanston, Illinois 60201

A в S T R A C T Toxemia was induced in 13 of 20 pregnant ewes by the stress of a change in environment and food deprivation late in pregnancy. Of the toxemic ewes, eight developed prominent neurological findings with convulsions, motor weakness, and blindness, whereas five ewes developed azotemia without neurological signs. Proteinuria and azotemia occurred in all but one of the toxemic animals. Seven animals did not develop clinical or laboratory evidence of toxemia. Hypertension did not occur with the onset of toxemia but all toxemic animals showed glomerular changes by light and electron microscopy. These abnormalities, which were similar to those seen in human preeclampsia, included endothelial cell swelling, focal reduplication of the basement membrane, and fusion of the epithelial cell foot processes. The toxemia could not be attributed to changes in hematocrit, plasma glucose, $\mathrm{Na}, \mathrm{Cl}, \mathrm{CO}_{2}, \mathrm{~K}, \mathrm{Ca}$, fibrinogen, arterial $\mathrm{pH}$, lactate, or pyruvate concentrations. Cardiac output fell only in ewes with prominent neurological signs. Plasma renin rose strikingly in animals developing toxemia, without change in substrate concentration. In contrast to human and other species, sheep uterus and amniotic fluid contained no detectable quantities of renin.

Thus in response to stress the pregnant ewe develops a toxemia which in the absence of hypertension has clinical and pathological similarities to human preeclampsia.

Dr. Ferris is a John and Mary R. Markle Scholar in Academic Medicine. This work was done during a Special Fellowship of the U. S. Public Health Service. Dr. Herdson's present address is the Department of Pathology, University of Auckland Medical School, Auckland, New Zealand. Dr. Lee's present address is St. Thomas Hospital, London, England.

Received for publication 28 January 1969 and in revised form 22 April 1969.

\section{INTRODUCTION}

Toxemic states of pregnancy are known to occur in various animal species although none has a presentation precisely similar to human preeclampsia (1). In the ewe the toxemic syndrome does bear a close resemblance to human eclampsia with proteinuria, azotemia, convulsions, and visual disturbances occurring usually in ewes with multiple or large fetuses. The condition appears in the latter part of pregnancy and is more frequent in animals allowed to gain excess weight during the pregnancy. It occurs spontaneously or can be induced experimentally by the stress of either starvation $(2,3)$ or a traumatic change in environment (4). The cause is unknown but has been variously attributed to ketosis, acidosis, and hypoglycemia.

The most obvious differences between ovine toxemia and human preeclampsia is the absence of hypertension in the ewe. Since the nonpregnant (5) and pregnant (6) sheep develop hypertension after renal artery constriction, this difference cannot be attributed merely to inability of the ewe to develop hypertension.

Since few clinical studies have been done in this disease, which bears a striking resemblance in many ways to human preeclampsia, and no investigations have been undertaken into the fine structure of the kidneys, this study reports the clinical, pathological, and physiological findings in pregnant ewes in which toxemia was induced by food restriction and a stressful change in environment.

\section{METHODS}

30 Herdwick ewes, 3-4 yr old, were mated in the autumn of 1966 and the mating date of each ewe was noted. 20 of these ewes were subsequently found to be pregnant. They were confined indoors for approximately 130 days at the 
TABLE I

Comparison of the Results of Investigations Carried

\begin{tabular}{|c|c|c|c|c|c|}
\hline & Weight & BP & Hct & $\mathrm{Na}$ & $\mathrm{K}$ \\
\hline & $K g$ & $m m H g$ & & $m E q /$ liter & $m E q /$ liter \\
\hline \multicolumn{6}{|c|}{ Group I (toxemic animals with neurological signs) } \\
\hline Control & $62 \pm 6.1$ & $115 \pm 10$ & $45 \pm 1.8$ & $149 \pm 1.6$ & $4.2 \pm 0.38$ \\
\hline Experimental & & $103 \pm 4.5$ & $45 \pm 4.5$ & $145 \pm 4.2$ & $4.0 \pm 0.68$ \\
\hline \multicolumn{6}{|c|}{ Group II (toxemic animals without neurological signs) } \\
\hline Control & $45 \pm 7.6$ & $99 \pm 6$ & $42 \pm 9.5$ & $145 \pm 4.7$ & $4.4 \pm 0.35$ \\
\hline Experimental & & $98 \pm 12.5$ & $36 \pm 12$ & $143 \pm 3.2$ & $3.8 \pm 0.45$ \\
\hline \multicolumn{6}{|c|}{ Group III (animals without clinical evidence of toxemia) } \\
\hline Control & $58 \pm 9.0$ & $104 \pm 10.2$ & $44 \pm 4.6$ & $145 \pm 3.2$ & $4.2 \pm 0.4$ \\
\hline Experimental & & $98 \pm 9.9$ & $39 \pm 5.2$ & $147 \pm 3.4$ & $4.2 \pm 0.5$ \\
\hline
\end{tabular}

$\mathrm{BP}=$ blood pressure $; \mathrm{SVR}=$ systemic vascular resistance.

Mean $\pm S D$ on first (control) and last (experimental) day of observation.

Agricultural Research Council Institute, Compton, Berkshire, England, where they were fed a high caloric diet. 1 month after mating, under pentobarbital anesthesia (20 $\mathrm{mg} / \mathrm{kg}$ ), the carotid artery of 15 of the 20 ewes subsequently found to be pregnant was exteriorized in a loop of skin. Between the 130th and 140th day of gestation the animals were transported by truck to the Radcliffe Infirmary, Oxford, a distance of approximately 20 miles. Upon arrival they were placed in individual pens and deprived of food but given free access to water. The 10 nonpregnant ewes were transported 130 days after mating to Oxford where five were killed upon arrival for control pathological studies and five were deprived of food for 3 or more days for control blood samples.

The day of transportation was considered day 1 and the animals were studied for up to 15 days until they had either died of toxemia or were killed. Venous blood samples were obtained from the jugular vein, usually at 2- to 3-day intervals, and analyzed for $\mathrm{Na}, \mathrm{K}, \mathrm{CO}_{2}$, urea, glucose, hematocrit, and renin. Determinations of plasma fibrinogen and calcium before and after the onset of toxemia were obtained in some animals. $\mathrm{Na}, \mathrm{K}, \mathrm{CO}_{2}, \mathrm{Cl}$, urea and glucose were done with an AutoAnalyser (Technicon), glucose being determined by the glucose oxidase method. Serum calcium was measured by a modification of the method of Baron and Bell (7) by use plasmocorinth $B$ as indicator. Plasma fibrinogen was measured by the method of Nilsson and Olow (8). Carotid artery samples for $\mathrm{pH}, \mathrm{pCO}_{2}$, and $\mathrm{pO}_{2}$ were measured in several animals using a $\mathrm{CO}_{2}$ and $\mathrm{O}_{2}$ electrode and a glass electrode $\mathrm{pH}$ meter (Radiometer Co., Copenhagen). Arterial pyruvate and lactate concentrations were determined by the enzymatic method, utilizing the Biochemica Kit supplied by C. F. Boehringer (Mannheim, Germany). Extinctions were determined with a Unicam spectrophotometer SP 500.

Plasma renin activity was measured by a modification of the method of Ryan, McKenzie, and Lee (9). $10 \mathrm{ml}$ of venous blood was anticoagulated with $20 \mathrm{mg}$ of ethylenediaminetetraacetate di-potassium salt (EDTA) and $2 \mathrm{ml}$ of the separated plasma was added to a sterile tube containing $20 \mathrm{mg}$ EDTA. $1 \mathrm{ml}$ of $0.1 \mathrm{M} \mathrm{PO}_{4}$ buffer, $\mathrm{pH} 6$, to which had been added Hibitane (Chlorhexidine, Imperial Chemical Industries) to a $0.01 \%$ concentration, $1 \mathrm{mg}$ soya bean trypsin inhibitor (SBTI), and two drops dimercaprol (BAL 0.05 $\mathrm{g} / \mathrm{ml}$ ) was mixed with the plasma and incubated $40 \mathrm{hr}$ at $42^{\circ} \mathrm{C}$ in a water bath. By use of this method sheep plasma was free of angiotensinase activity for up to $48 \mathrm{hr}$. The reaction was stopped by freezing and the angiotensin formed was assayed in a ganglion-blocked, anesthetized rat using Val-5-angiotensin-11-B-amide (Hypertensin-CIBA) as the standard. The renin activity was expressed as nanograms of angiotensin generated in $1 \mathrm{hr} / 100 \mathrm{ml}$ plasma. Renin substrate concentration was measured in each plasma sample by incubating $0.2 \mathrm{ml}$ EDTA-treated plasma with $1.4 \mathrm{ml}$ of $0.1 \mathrm{M} \mathrm{PO}$ buffer, $\mathrm{pH} 6$, and $0.4 \mathrm{ml}$ of an angiotensinase-free preparation of rabbit renin prepared by a method previously reported (10). This mixture was incubated for $2 \mathrm{hr}$ and the reaction stopped by boiling for $10 \mathrm{~min}$. The angiotensin formed was assayed in the usual manner and expressed as nanograms of angiotensin per milliliter of plasma.

Tissue renin extractions were performed by the modified method of Haas and Gøldblatt (11). Tissues were homogenized in a blender with distilled water, $1 \mathrm{ml} / \mathrm{gm}$ wet weight of tissue, followed by acid precipitation by titration with $2 \mathrm{~N}$ $\mathrm{H}_{2} \mathrm{SO}_{4}$ to $\mathrm{pH} 2.5$ for $10 \mathrm{~min}$. After neutralization of the extract with $5 \mathrm{~N} \mathrm{KOH}$ the supernatant was precipitated with $1.6 \mathrm{M}\left(\mathrm{NH}_{4}\right)_{2} \mathrm{SO}_{4}$ and this precipitate resuspended in distilled water and dialyzed in a bath of isotonic saline and $3.6 \mathrm{~mm}$ EDTA for $24 \mathrm{hr}$ at $4^{\circ} \mathrm{C}$. A second dialysis for 24 $\mathrm{hr}$ in distilled water to remove the EDTA was done, the extract thus obtained was centrifuged and the supernatant removed and made isotonic by the addition of hypertonic saline. All extracts were kept frozen at $-10^{\circ} \mathrm{C}$.

Cardiac output was measured in the conscious animal with exteriorized carotid artery by a modification of the method of Sparling et al. (12) and Emanuel et al. (13). The animals were given heparin $2 \mathrm{mg} / \mathrm{kg}$ intravenously and blood was withdrawn from the carotid artery and returned through a cuvette densitometer into the jugular vein. Cardiac output was calculated by the standard formula. The cardiac output was measured three times in each animal over a $15 \mathrm{~min}$ period and the mean of the three determinations was considered the output. Variations of between 10 and $15 \%$ occurred in individual output measurements but mean outputs from day to day in individual animals were quite reproducible.

In several ewes the pressor effect of a standard infusion of Val-5-angiotensin-11-B-amide, $25 \mathrm{ng} / \mathrm{kg}$ per min, was 
Out on the First and Last Day of Observation

\begin{tabular}{|c|c|c|c|c|c|c|}
\hline $\mathrm{CO}_{2}$ & $\mathrm{Cl}$ & Glucose & Urea & Plasma renin & Cardiac output & SVR \\
\hline mmoles/liter & $m E q /$ liter & $m g / 100 \mathrm{ml}$ & $m g / 100 \mathrm{ml}$ & $m \mu g / 100 \mathrm{ml} \mathrm{per} \mathrm{hr}$ & $m l / k g$ per min & dyne-sec- $\mathrm{cm}^{-5}$ \\
\hline $19 \pm 3.3$ & $103 \pm 3.5$ & $60 \pm 31.3$ & $24 \pm 6.9$ & $109 \pm 62.8$ & $101 \pm 25$ & $1526 \pm 421$ \\
\hline $15 \pm 4.3$ & $105 \pm 2.3$ & $41 \pm 13.7$ & $78 \pm 43.6$ & $1204 \pm 676$ & $70 \pm 40.4$ & $2220 \pm 833$ \\
\hline $20 \pm 3.6$ & $102 \pm 6.4$ & $63 \pm 28.6$ & $34 \pm 2.2$ & $147 \pm 66.4$ & $130 \pm 65.5$ & $1526 \pm 547$ \\
\hline $17 \pm 4.3$ & $102 \pm 4.4$ & $59 \pm 11.4$ & $155 \pm 59$ & $826 \pm 408$ & $112 \pm 34.4$ & $1670 \pm 690$ \\
\hline $19 \pm 2.7$ & $103 \pm 2.9$ & $81 \pm 27$ & $28 \pm 7.1$ & $88 \pm 24$ & $114 \pm 22$ & $1343 \pm 327$ \\
\hline $18 \pm 4.7$ & $106 \pm 2.7$ & $56 \pm 12.4$ & $31 \pm 7.4$ & $202 \pm 52$ & $109 \pm 17.8$ & $1294 \pm 161$ \\
\hline
\end{tabular}

determined and this sensitivity was followed through the period of development of toxemia.

In four animals indwelling catheters were inserted into the bladder on day 1 and complete urine collections made throughout the period of observation. Since acute pyelonephritis was present in these animals at postmortem, all subsequent urine samples were obtained by single catheterizations with the ewe under light nembutal anesthesia. Urinary acetone was tested with acetest tablets (Ames Co., Inc.) and urinary protein measured by the biuret method (14).

Animals which did not die of toxemia were killed with intravenous pentobarbital and portions of kidney, heart, uterus, placenta, liver, adrenal, and peripheral nerve fixed in $10 \%$ formol saline. The brain was removed in most animals and similarly fixed in formol saline. Brain and peripheral nerve were stained with $\mathrm{H} \& \mathrm{E}$, Weil-hematoxylin, hematoxylin and Van Gieson's stain, and Cresyl violet for Nissl granules. Other tissues were stained with $H \& E$, Goldner's modification of Masson Tri-Chrome, periodic acidSchiff, and Hart's modification of Weigert's elastic stain.

Electron microscopy. Using a dissecting microscope, sections of renal cortex were taken and cut into blocks approximately $2 \mathrm{~mm}^{3}$ in size. These blocks were fixed in phosphatebuffered or cacodylate-buffered $4 \%$ glutaraldehyde $(\mathrm{pH} \mathrm{7.3)}$ at $4^{\circ} \mathrm{C}$ for $5-24 \mathrm{hr}$, and then trimmed to about $1 \mathrm{~mm}^{3}$ to include at least one glomerulus and rinsed overnight at $4^{\circ} \mathrm{C}$ in phosphate or cacodylate buffer ( $\mathrm{pH} 7.3$ ) containing $5 \%$ sucrose. The blocks were then postfixed in phosphate-buffered osmium tetroxide ( $\mathrm{pH} 7.3)$ at $4^{\circ} \mathrm{C}$ for $1-2 \mathrm{hr}$, dehydrated through graded alcohols at room temperature, and embedded in Araldite or Epon 812. Sections were cut on a Porter-Blum MT-1 ultramicrotome by use of glass knives. Sections $0.5 \mu$ thick from each block were mounted on glass microscope slides, stained with toluidine blue, and examined by light microscopy. Ultra-thin sections were mounted on plain Effa grids, stained with lead, and examined in a Philips EM 200 electron microscope.

\section{RESULTS}

\section{Clinical}

By clinical criteria the animals could be divided into three groups (Table I). Animals in group I and II de- veloped toxemia with listlessness and lethargy within 2-3 days after a change in environment and food deprivation and all but one became azotemic (blood urea > $40 \mathrm{mg} / 100 \mathrm{ml}$ ). Animals in group III did not show any signs of toxemia. Sheep in groups I and II showed a striking loss of wool, and animals which lived 10 days with toxemia had virtually complete loss of wool from their backs and what remained could easily be removed by pulling. The toxemic animals were differentiated into two groups by the overt neurological findings occurring in eight sheep (group I). Seven of the eight animals of this group developed severe motor weakness usually generalized, but in three the weakness began in the hind legs and progressed over the ensuing $24-48 \mathrm{hr}$ until the animals were unable to assume the erect posture. The motor weakness usually began within $3-4$ days after stressing the animals but one animal began to drag its hind limb within $36 \mathrm{hr}$ of arrival. The one animal of this group which did not have motor weakness developed bilateral blindness with complete loss of a pupillary light reflex. Three animals died within $48 \mathrm{hr}$ of the onset of motor weakness and two were killed when paralysis was first noted. Weakness of the muscles involved in swallowing with frothing from the mouth was present in some group I animals. Convulsions with clonic movements of the head, facial muscles, and extremities were noted in three animals but a postictal period of unconsciousness was noted in only one animal. An unusual dainty gait often preceded the motor weakness and may have been indicative of painful extremities. A sensory deficit could not be ascertained since the animals seemed to respond to painful stimuli even when severe motor weakness was present. Three animals of group I developed loose stools but severe diarrhea did not occur. Ophthalmoscopic examination of all toxemic animals failed to reveal papilledema, hemorrhages, or exudates. 
Animals in group II did not develop neurological signs and none died as a result of toxemia. Although azotemia was usually more striking in these sheep than in those of group I, none appeared moribund, and although listless, all lived until they were killed for pathological studies.

A striking feature of the eight animals of group I was the presence of twin lambs in six animals. By contrast, there were no twin-bearing ewes in group II or III. Thus all ewes bearing twins developed toxemia together with prominent neurological signs.

Ewes, in group I weighed more $(62 \pm 6.1 \mathrm{~kg})$ than those in group II $(44 \pm 7.6 \mathrm{~kg})$. However group III ewes which did not develop signs of toxemia had a mean weight ( $58 \pm 9.0 \mathrm{~kg}$ ) approximately the same as animals in group $\mathrm{I}$.

Blood pressure did not rise with the onset of toxemia. A fall in blood pressure was usually noticed in animals with neurological involvement when paralysis occurred. Although mean systemic peripheral resistance increased in group I animals with the onset of toxemia the difference was not statistically significant.

\section{Laboratory findings}

A comparison of the results of investigations carried out on the first and last day of observation in the three groups of animals are given in Table I. Mean values of all bicarbonate, urea, glucose, and cardiac output

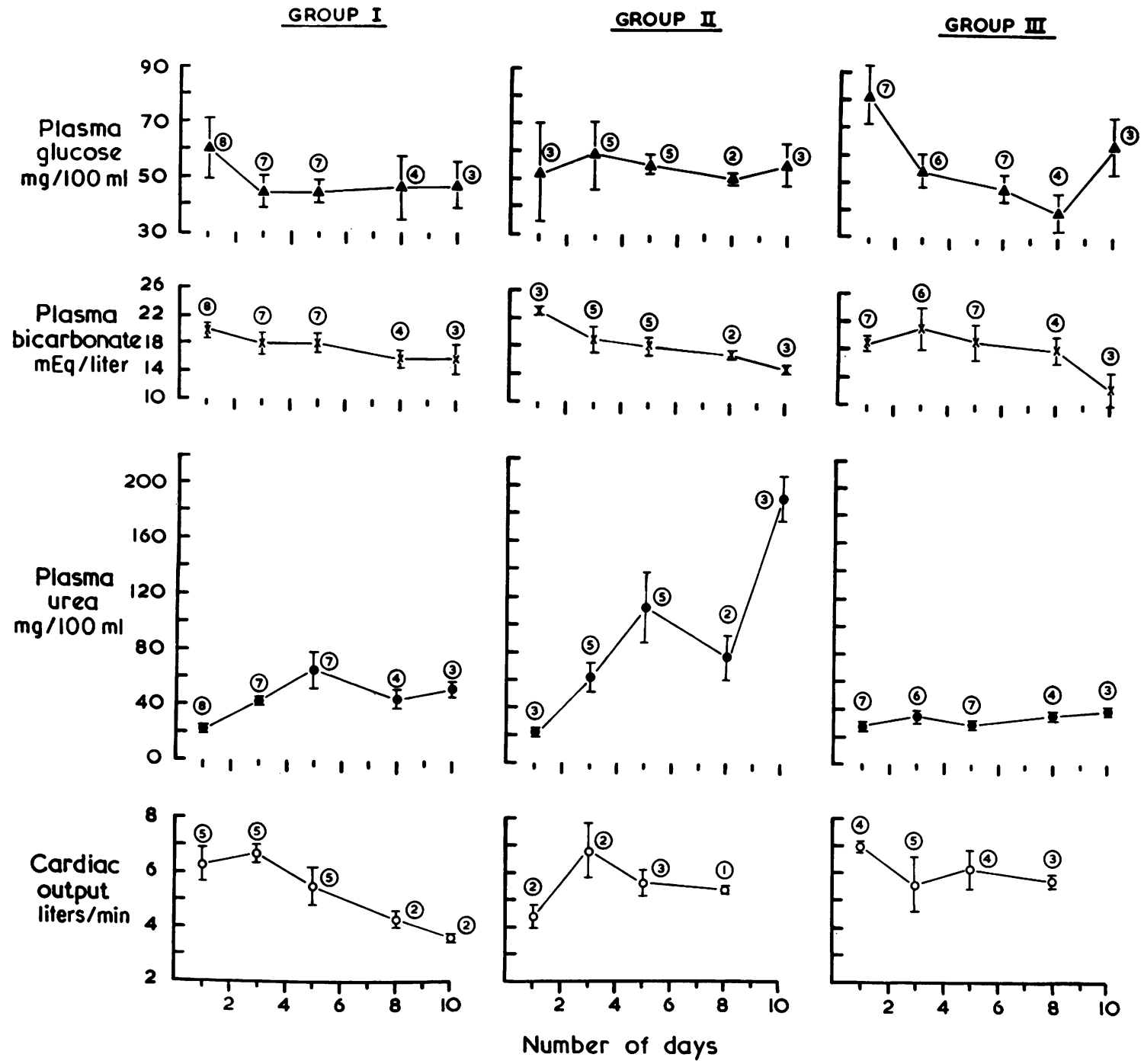

FIGURE 1 Mean and SE of plasma glucose, bicarbonate, urea, and cardiac output of the three groups of animals during induction of toxemia. Group I, toxemic with neurologic signs; group II, toxemic without neurologic signs; group III, animals without toxemia. 


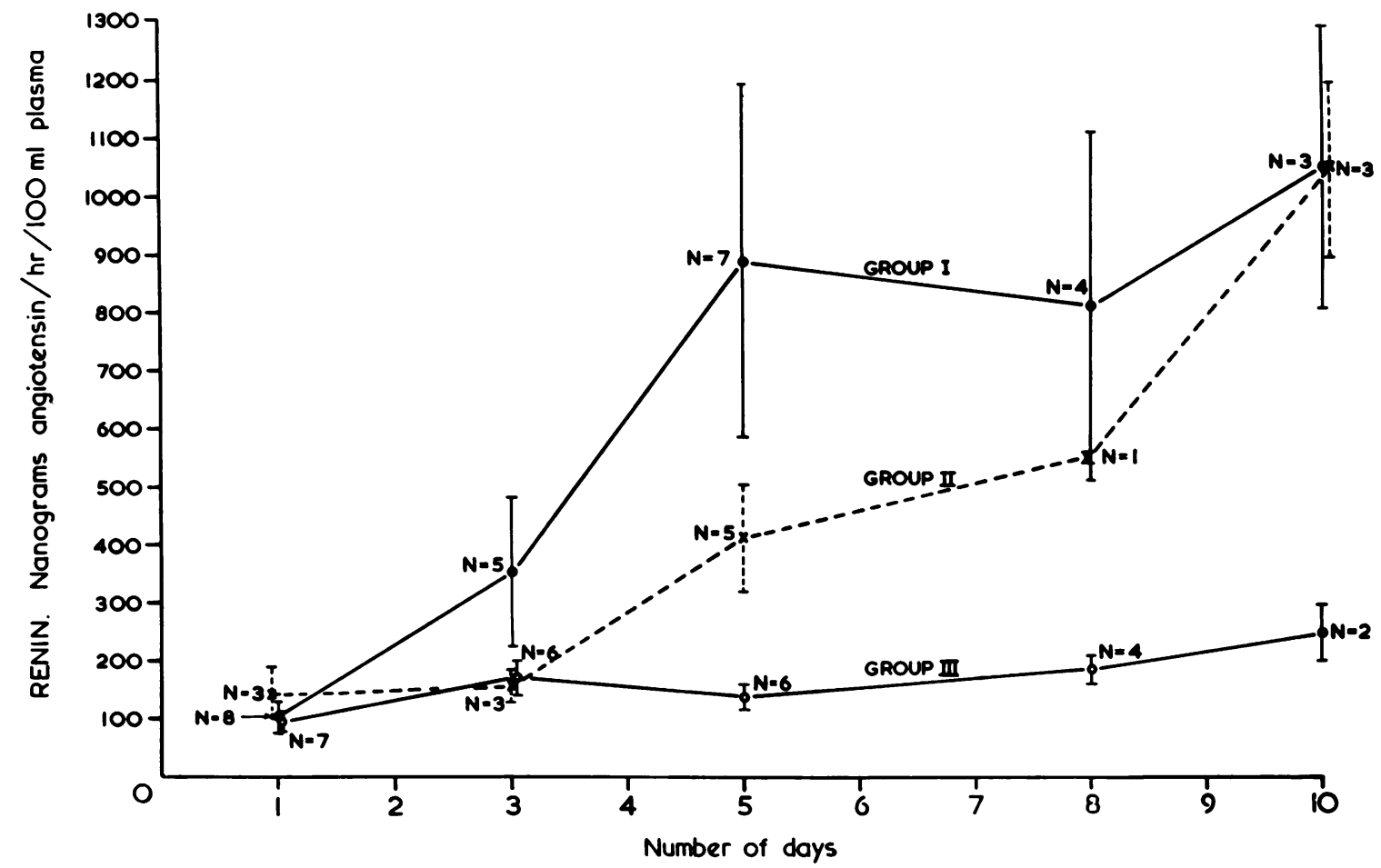

FIGURE 2 Mean and SE of changes in plasma renin during induction of toxemia in the three groups of animals. Note the absence of a rise in plasma renin in group III which did not develop toxemia.

measurements over a 10 days period are shown in Fig. 1. The variability in the number of observations from day to day in each group results primarily from death or sacrifice of animals at various times during the 10 day period.

There was no significant difference in plasma glucose in the three groups, and plasma glucose levels did not correlate with the development of neurological signs. Thus, animals with severe neurological involvement did not have striking hypoglycemia and $100 \mathrm{~g}$ of glucose given intravenously to animals with motor weakness had no effect upon the paralysis.

There was no significant difference in plasma bicarbonate in the three groups during the course of the study. Although the low bicarbonate concentration previously reported in ovine toxemia has been presumed to be a manifestation of metabolic acidosis, in 11 out of 14 occasions when arterial $\mathrm{pH}$ and $\mathrm{pCO}_{2}$ were measured in nine animals an alkalosis was present. The animal's agitation may have been a factor in acutely lowering $\mathrm{pCO}_{2}$ with a resultant respiratory alkalosis being present or a compensated respiratory alkalosis may be a feature of ovine pregnancy.

Since measurements of arterial $\mathrm{pH}$ were not made in every animal and serial measurements were not obtained in group II where uremia was a prominent feature of the toxemia, we cannot exclude the development of an acidosis as uremia progressed in some animals.

All animals with toxemia developed azotemia (urea > $40 \mathrm{mg} / 100 \mathrm{ml}$ ) except for one which had neurological abnormalities. Mean urea was higher in animals without neurological signs (group II). There was no change in plasma urea in group III animals. Reversibility of the azotemia was noted in one animal which lambed on day 5. Urea fell from $148 \mathrm{mg} / 100 \mathrm{ml}$ to $40 \mathrm{mg} / 100 \mathrm{ml}$ over the next 4 days. There was no correlation between changes in cardiac output and plasma urea levels. Azotemia developed in five animals with no reduction in cardiac output.

In four of the five ewes in group I with measured cardiac outputs, there was a decline in output as the neurological manifestations became prominent. The cause of this fall in cardiac output in animals with neurological signs is not clear. Severe anoxia was not present in the three ewes with motor weakness in which it was measured.

There was a proportional elevation of both arterial lactate and pyruvate concentrations in most animals and this may have been related to the presence of respiratory alkalosis. No increase in lactate or pyruvate concentration occurred with toxemia and no "excess lactate" (15) production was noted. There was no consistent 
change in plasma $\mathrm{Ca}$, fibrinogen, or bilirubin in animals developing toxemia. One ewe did have a fall in hematocrit but without evidence of blood loss clinically or at postmortem. Two other ewes which did not develop toxemia had similar unexplained falls in hematocrit. Although weights were not followed during the course of the toxemia, hemodilution would be an unlikely explanation for these reductions in hematocrit since dilution of this magnitude in animals receiving no salt intake should have lowered plasma $\mathrm{Na}$ concentration.

All toxemic animals except one had proteinuria. In 8 of 14 toxemic ewes protein was present in the first urine sample, but in five proteinuria developed during the course of the toxemia. Five of six animals in group III had proteinuria; three on the initial urinalysis and two developed proteinuria during the observation period. In four toxemic animals with indwelling catheters, $24 \mathrm{hr}$ protein excretion ranged from 2.4 to $7.3 \mathrm{~g}$. Random urines of the toxemic animals revealed hyaline and granular casts but microscopic hematuria was not noted.

Some toxemic animals developed acetonuria with fasting but others did not. The presence of acetonuria was not related to either the presence of toxemia or to particular signs occurring with toxemia. Three of the six animals in group III developed acetonuria with no evidence of toxemia.

Plasma renin activity rose dramatically in all toxemic animals and was the best biochemical indicator of the development of toxemia (Fig. 2). Loose stools developed only in some group I animals and no change in serum $\mathrm{Na}$ occurred in the toxemic animals. Extraordinary $\mathrm{Na}$ loss would not seem to explain the striking rise in plasma renin activity. In contrast, group III had only a slight rise in renin activity over the $\mathbf{1 0}$ day period. The more rapid rise of plasma renin in animals with neurological signs may be the result of the greater severity of the illness, the fall in cardiac output, and some $\mathrm{Na}$ loss through diarrhea in this group.

Plasma renin substrate concentrations were between 250 and $500 \mathrm{ng}$ angiotensin/cc plasma and no consistent change in substrate concentration occurred with the appearance of toxemia. After a $40 \mathrm{hr}$ incubation with normal plasma renin values of approximately $100 \mu \mathrm{g} / 100$ cc per hr between 12 and $16 \%$ of the available substrate is utilized. When plasma renin activity increased substrate concentration undoubtedly became rate limiting in the reaction but the greater substrate utilization at higher plasma renin levels would have underestimated actual plasma renin activity compared with control values. Thus the increase in plasma renin activity as toxemia progressed is more striking when one considers that substrate concentrations remained stable.

Angiotensin infusions were done in four toxemic animals using a dose of $25 \mathrm{ng}$ angiotensin/ $\mathrm{kg}$ per min ( $\mathrm{Hy}-$ pertensin-CIBA) which initially caused a $20-30 \mathrm{~mm} \mathrm{Hg}$ rise in systolic pressure in all animals but as toxemia progressed the pressor response to the angiotensin became markedly diminished. In two animals no rise in blood pressure occurred with this dose of angiotensin 8-10 days after the induction of toxemia and in two other ewes initial responses of $20-22 \mathrm{~mm} \mathrm{Hg}$ fell to 8-10 $\mathrm{mm} \mathrm{Hg}$ on day 5 .

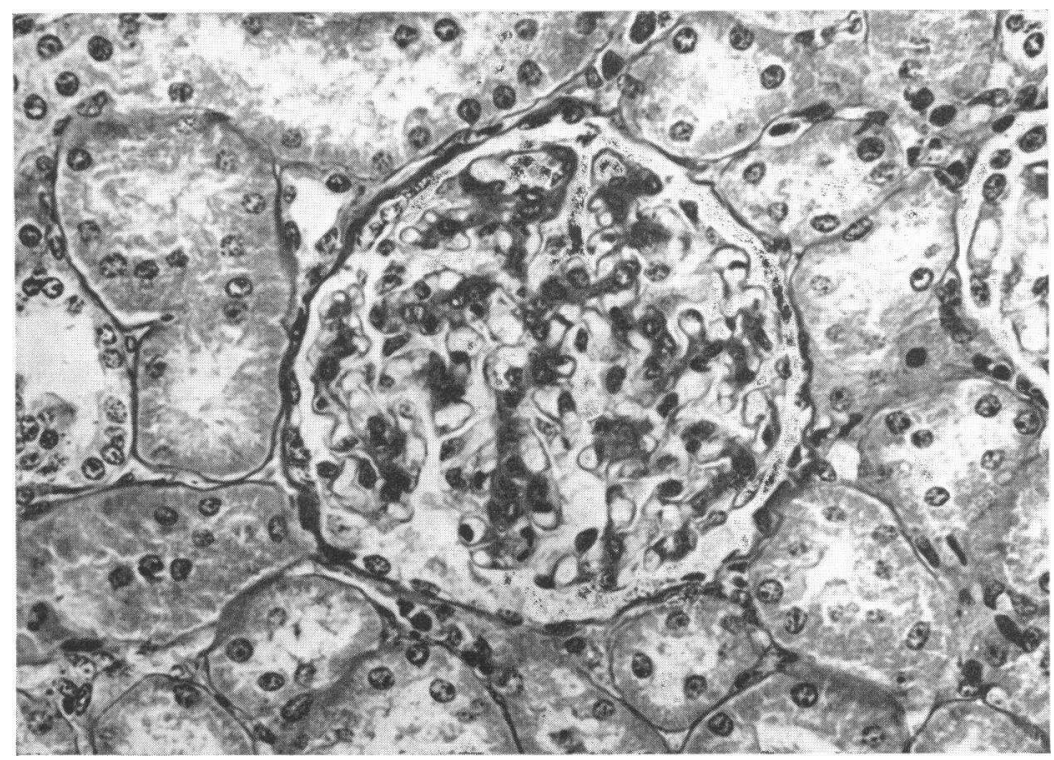

FIGURE 3 Normal glomerulus in a nonpregnant sheep. Hematoxylin and eosin. $\times 380$. 


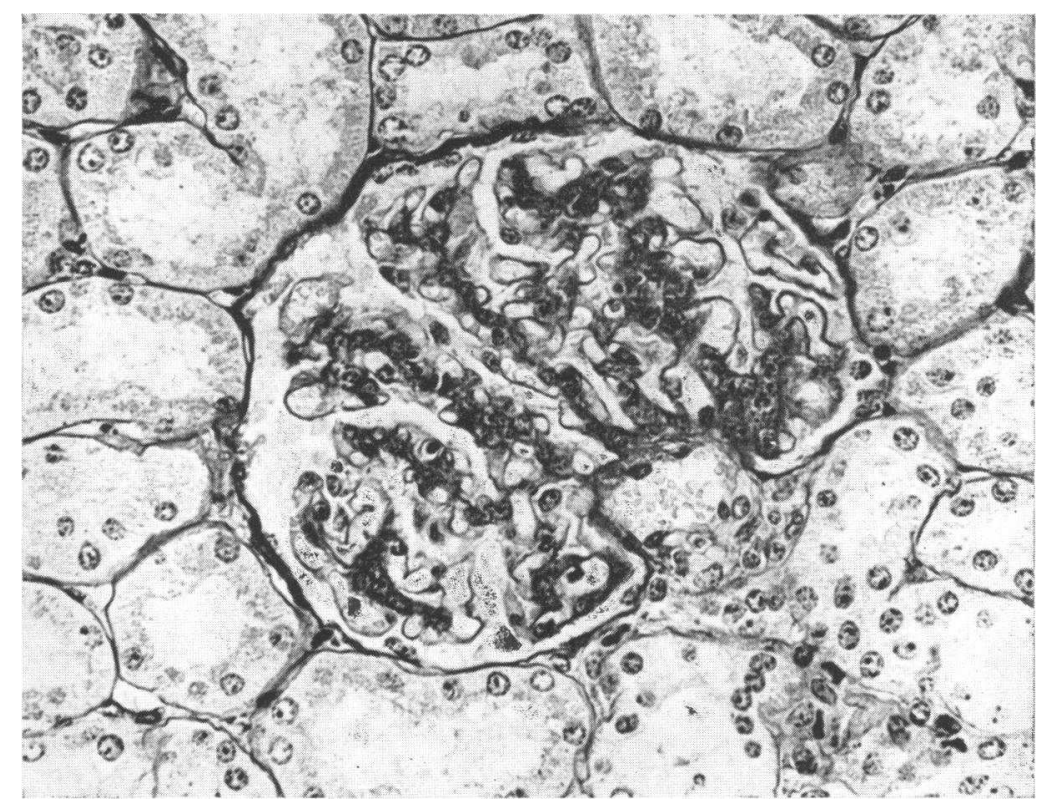

FIgUre 4 Normal glomerulus in a nonpregnant sheep. Periodic acid-Schiff. $\times 380$.

Uteri from toxemic and normal pregnant animals were extracted for renin and no activity was detected by assay of the extract in the ganglion-blocked rat. Sheep kidney extracts prepared in a similar fashion always demonstrated renin activity. Amniotic fluid from animals with and without toxemia incubated for $40 \mathrm{hr}$ in a system containing sheep substrate failed to generate angiotensin. This amniotic fluid system was found to be free of angiotensinase activity for the period of incubation.

\section{Pathology}

\section{KIDNEYS}

Macroscopic appearances. In all three groups of pregnant sheep, the kidneys were of unremarkable gross appearance and were similar to those from nonpregnant sheep. In particular, the subcapsular surfaces were smooth, without evidence of hemorrhage, and the cut surfaces showed cortices well demarcated from medullae, with normal papillae, calyces, and pelves. In the four sheep which had had indwelling catheters there were focal changes consistent with acute pyelonephritis, which was confirmed by light microscopy.

Light microscopy. (a) Nonpregnant controls. The histological appearances of renal cortex and medulla from nonpregnant control sheep conformed to previous descriptions of sheep kidney. In particular, the glomeruli showed a distinct lobular pattern (Figs. 3 and 4) with individual capillary loops lined by a thin "basement membrane" as seen in sections stained by the periodic acid-Schiff method (PAS) (Fig. 4). The glomeruli were relatively cellular, with the majority of the cells being intracapillary and having densely staining nuclei and faintly eosinophilic cytoplasm. Epithelial cells were unremarkable.

(b) Pregnant sheep, without toxemia. Kidneys from sheep in group III were of similar histological appearances to those from nonpregnant controls, except that in those animals in which proteinuria was found, glomeruli showed mild mesangial thickening and slight mesangial hypercellularity.

(c) Toxemic sheep. The kidneys from all animals which showed evidence of toxemia, in both groups I and II, showed histological abnormalities of the glomeruli. All the glomeruli were diffusely involved, and appeared to be enlarged, with capillary tufts virtually filling Bowman's space. In many cases, there was an accentuation of the lobular pattern (Fig. 5), and most of the glomeruli appeared relatively bloodless, with varying degrees of obliteration of capillary lumina (Fig. 6). Many glomeruli showed a rather "smudgy" appearance of both the mesangial and peripheral regions of capillary loops. There was no significant increase in the cellularity of these abnormal glomeruli, nor was there any increase in the number of polymorphonuclear leukocytes. PASstained sections showed focal thickening of glomerular capillary "basement membranes."

These changes, which were present in the glomeruli of all toxemic sheep, tended to be more pronounced in 


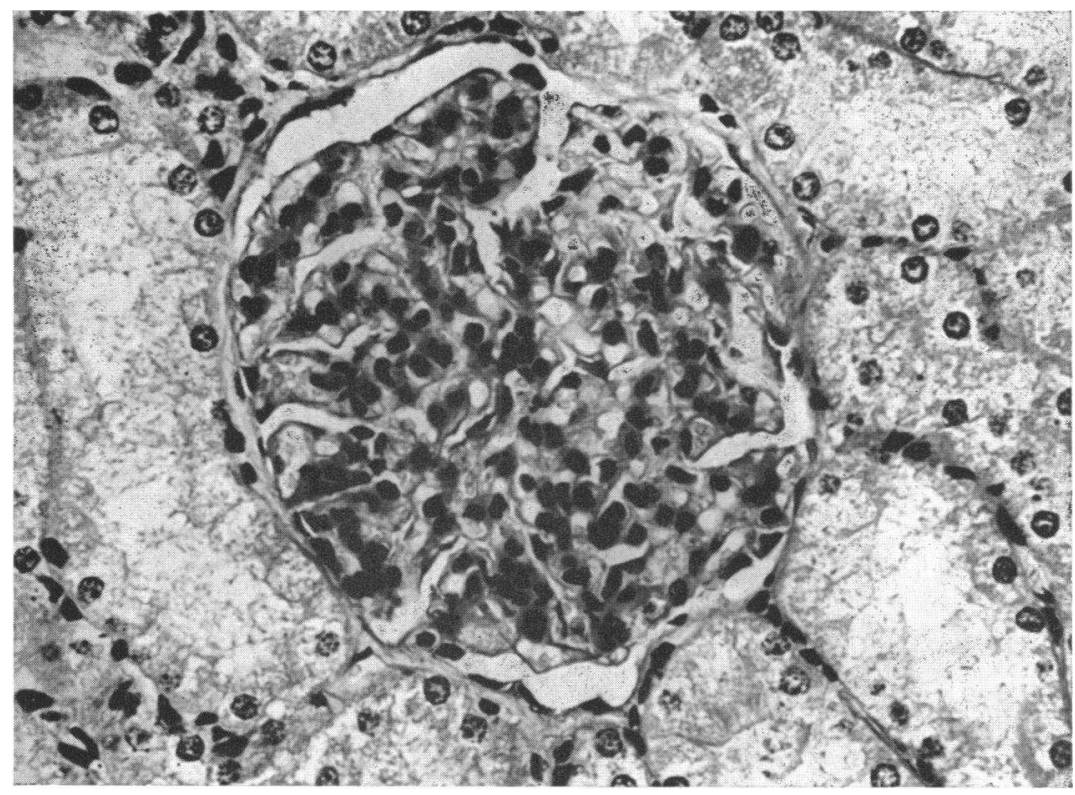

FigURE 5 Moderately affected animal (group I), showing focal capillary obliteration and tuft adhesions. Hematoxylin and eosin. $\times 380$.

the kidneys from animals of group II, where in addition, occasional adhesions between lobules and Bowman's capsule were seen.

Apart from the glomerular abnormalities, the histological appearances of the kidneys from both groups of toxemic sheep were similar to controls, except for the presence of proteinaceous material within the lumen of many tubules. In particular, there was no evidence of interstitial edema, fibrosis, or inflammation, nor of vascular disease or fibrin deposition in capillaries.

Electron microscopy. (a) Nonpregnant controls. The fine structure of renal glomeruli from nonpregnant control sheep is illustrated in Figs. 7 and 8. In the peripheral part of each capillary loop, endothelium is seen to be

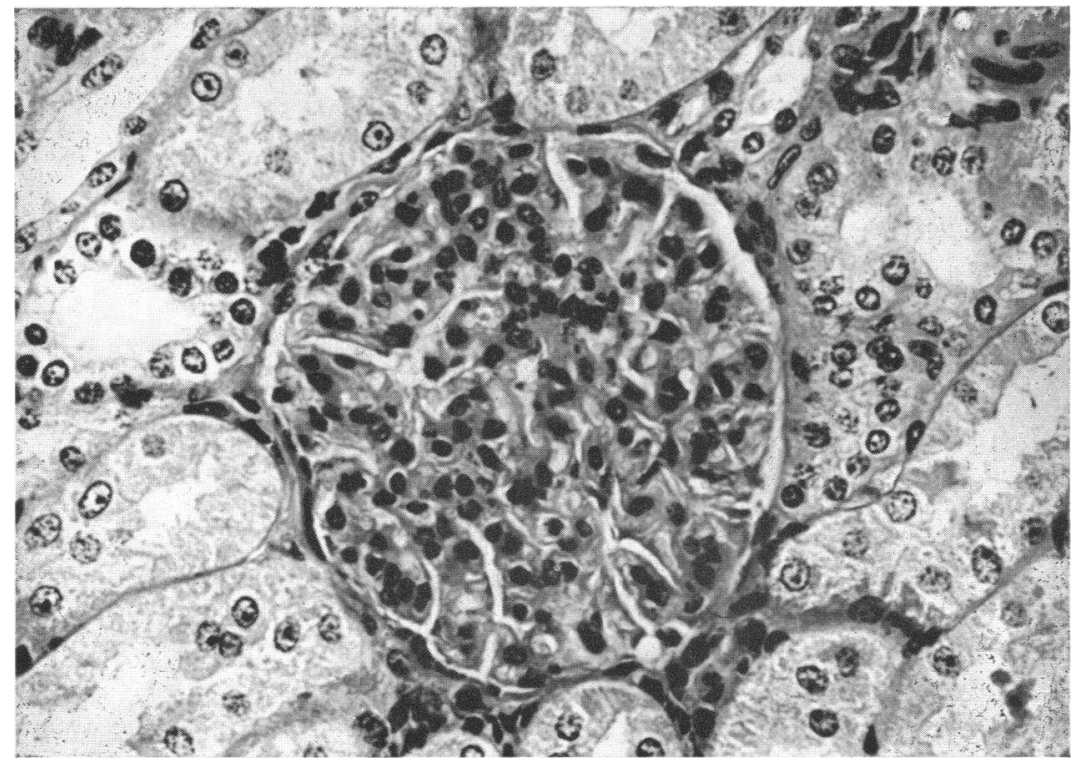

FIGURE 6 Glomerulus from a toxemic sheep (group II) with severe azotemia. The glomerulus appears bloodless, and the tuft completely fills Bowman's space. Hematoxylin and eosin. $\times 380$. 


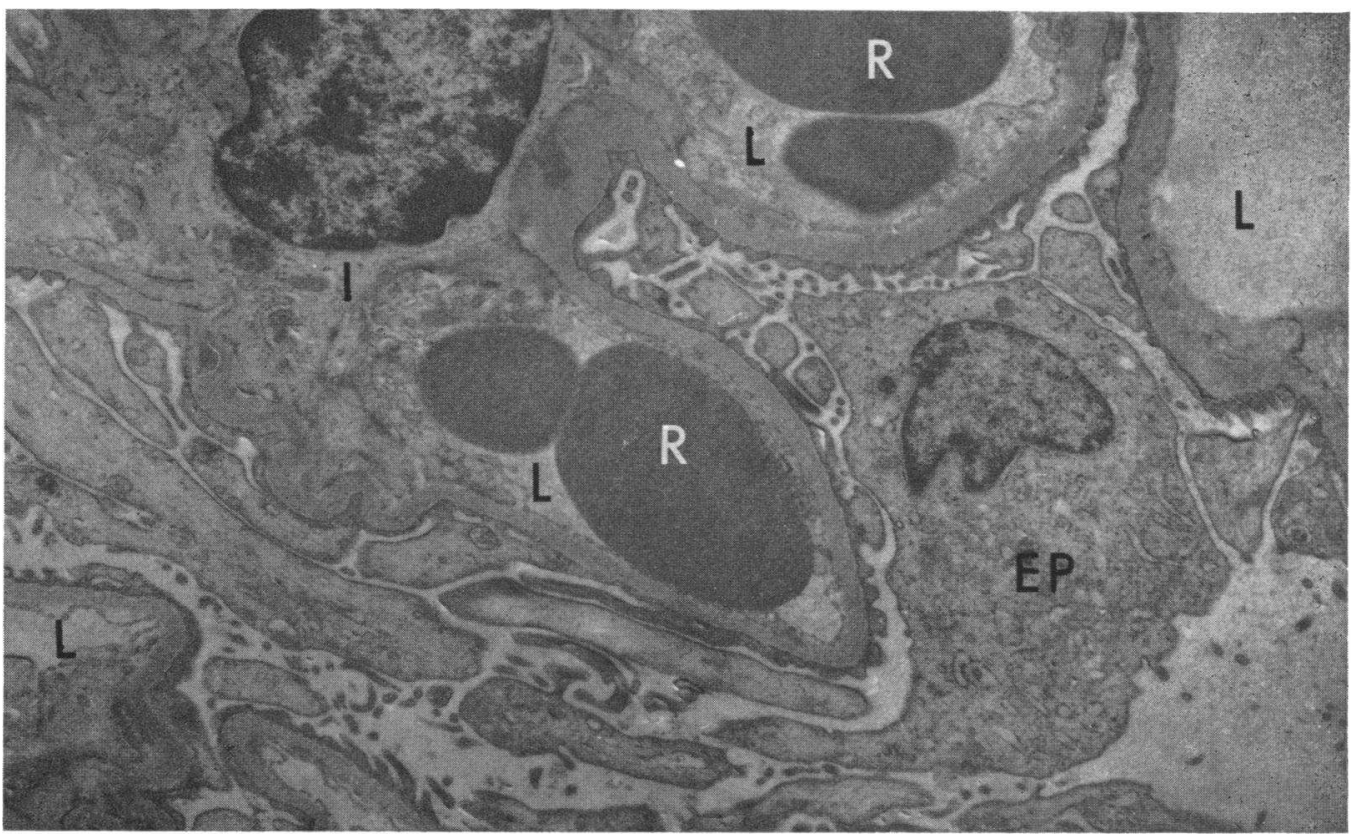

Figure 7 Control nonpregnant sheep. Part of a glomerulus, showing sections of several capillary loops. $L$, capillary lumen; $R$, red blood cell ; $I$, intracapillary (mesangial) cell ; $E P$, epithelial cell. There is relatively little basement membrane-like intercellular matrix in the mesangium. Glomeruli from pregnant nontoxemic sheep were of similar fine structure. $\times 8000$.

closely applied to the basement membrane, along the outer aspect of which discrete epithelial foot processes are seen. With the method of fixation used in the present study, the basement membrane shows minimal evidence of a discrete lamina densa and internal and external laminae rara.

(b) Pregnant, nontoxemic sheep. The fine structure of renal glomeruli from sheep in group III did not differ significantly from those of nonpregnant controls.

(c) Toxemic sheep. All the renal glomeruli examined from toxemic sheep in both groups I and II showed fine structural abnormalities (Figs. 9 and 10). The mesangium was unusually prominent, with basement membrane-like material lying between the cells (Fig. 9). Many capillary lumina were markedly occluded by endothelial cytoplasm, and there was a reduplication of base- ment membranes in the peripheral portions of many loops (Fig. 9). Intracapillary cell cytoplasm lay between these reduplicated basement membranes (Figs. 9 and 10), giving a mesangial-like appearance to peripheral parts of these loops. In other areas capillary loops appeared relatively normal. No electron-dense deposits were seen either within the basement membranes or on their epithelial aspects. Epithelial cells showed widespread fusion of their foot processes, together with extensive microvillation. However, all glomeruli included some loops in which discrete epithelial foot processes were present. Fibrin was not seen in any of these abnormal glomeruli.

These glomerular fine structural alterations were present to a similar extent in the kidneys of sheep from both group I and II. No definite correlation could be estab-

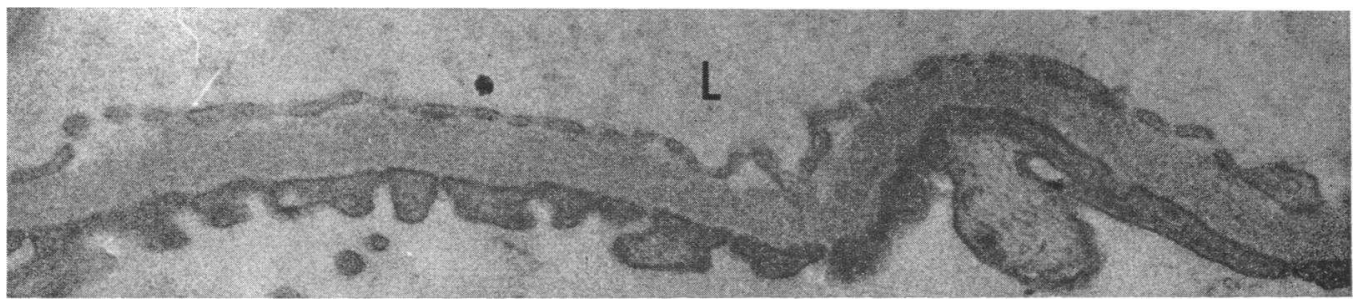

FIGURE 8 Control nonpregnant sheep. A segment of peripheral capillary loop of a glomerulus. $L$, capillary lumen. The fenestrated endothelium, homogeneous basement membrane, and epithelial foot processes are clearly shown. $\times 26,000$. 
lished between the degree of fine structural change and the clinical severity of toxemia.

\section{LIVER}

Grossly the livers from nonpregnant controls and pregnant nontoxemic (group III) sheep were unremarkable. Histologically all but one of the livers from the toxemic sheep of group I showed severe centrilobular fatty change. Much less severe fat accumulation was found in the livers from all of the toxemic sheep in group II.

\section{Adrenals, Uteri, Brain, and Peripheral Nerve}

In all groups, there were no gross or microscopic abnormalities of the adrenals or uteri from any animals. No pathological changes were seen in either brain or peripheral nerve. The changes in cerebral cortex and cerebellum associated with hypoglycemia were absent.

\section{DISCUSSION}

Although previous studies have emphasized the metabolic derangements in ovine toxemia our findings indicate that these changes are the result of starvation rather than the cause of the disease. Since starvation is used to induce the condition and since anorexia is a feature of the spontaneously occurring disease, all studies of ovine toxemia have taken place against a background of insufficient food intake. Thus hypoglycemia bore no relationship to either the presence of toxemia or to whether neurological signs developed. This failure to demonstrate a correlation between hypoglycemia and toxemia has been reported by others (16). Hypoglycemia seems to be a reflection of high fetal demand for glucose since experiments have shown it to be ameliorated by fetal death or delivery (17). Similarly, severe acidosis did not occur and lactic acid did not accumulate as occurs in some human conditions associated with hypoglycemia (18).

Since there was no fall in blood pressure and cardiac output did not fall in five of the twelve azotemic animals previous assumptions that the azotemia was a manifestation of prerenal reduction in renal blood flow seem unjustified. The presence of a glomerular lesion by both light and electron microscopy was a constant finding in toxemic animals and would seem to explain adequately the azotemia which occurred.

The renal changes present in ovine toxemia are similar in most respects to those seen in human toxemia (19-21). In both species the morphological abnormalities affect the glomeruli, which are uniformly involved. By light microscopy, Baird and Dunn (19) demonstrated a general enlargement of glomeruli in human toxemia, and this is seen in sheep. Similarly in both

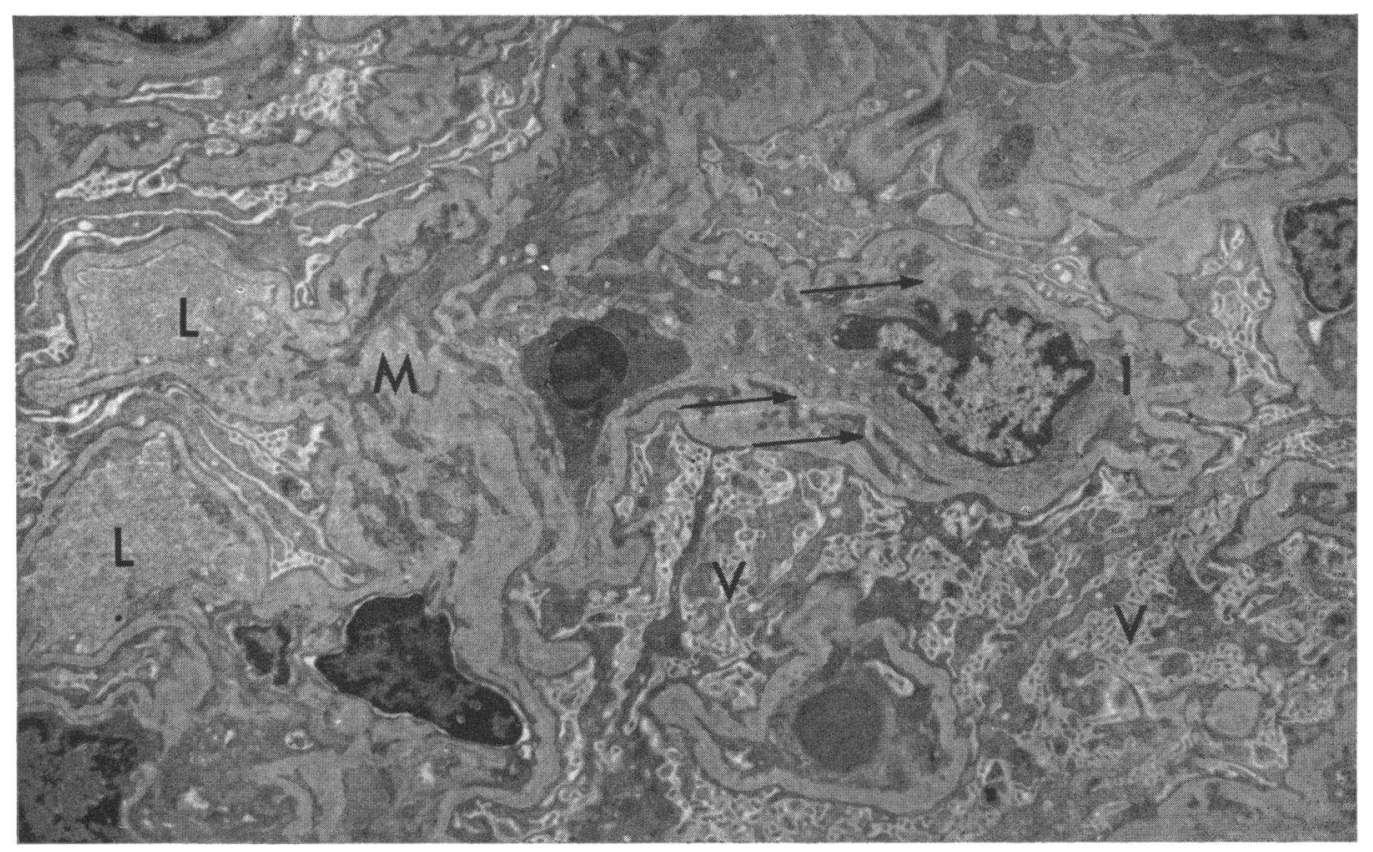

FIgUre 9 Toxemic sheep (group II). Part of a glomerulus, showing sections of several capillary loops. There is widespread fusion of epithelial foot processes, and epithelial cell microvillation $(V)$ is present. Some loops are virtually occluded by intracapillary cells (e.g. I), and reduplication of basement membrane is seen frequently (arrows). The mesangium $(M)$ is enlarged, with much intercellular basement membrane-like material present. Some loops retain patent lumens $(L)$ and relatively normal fine structure. $\times 4500$. 


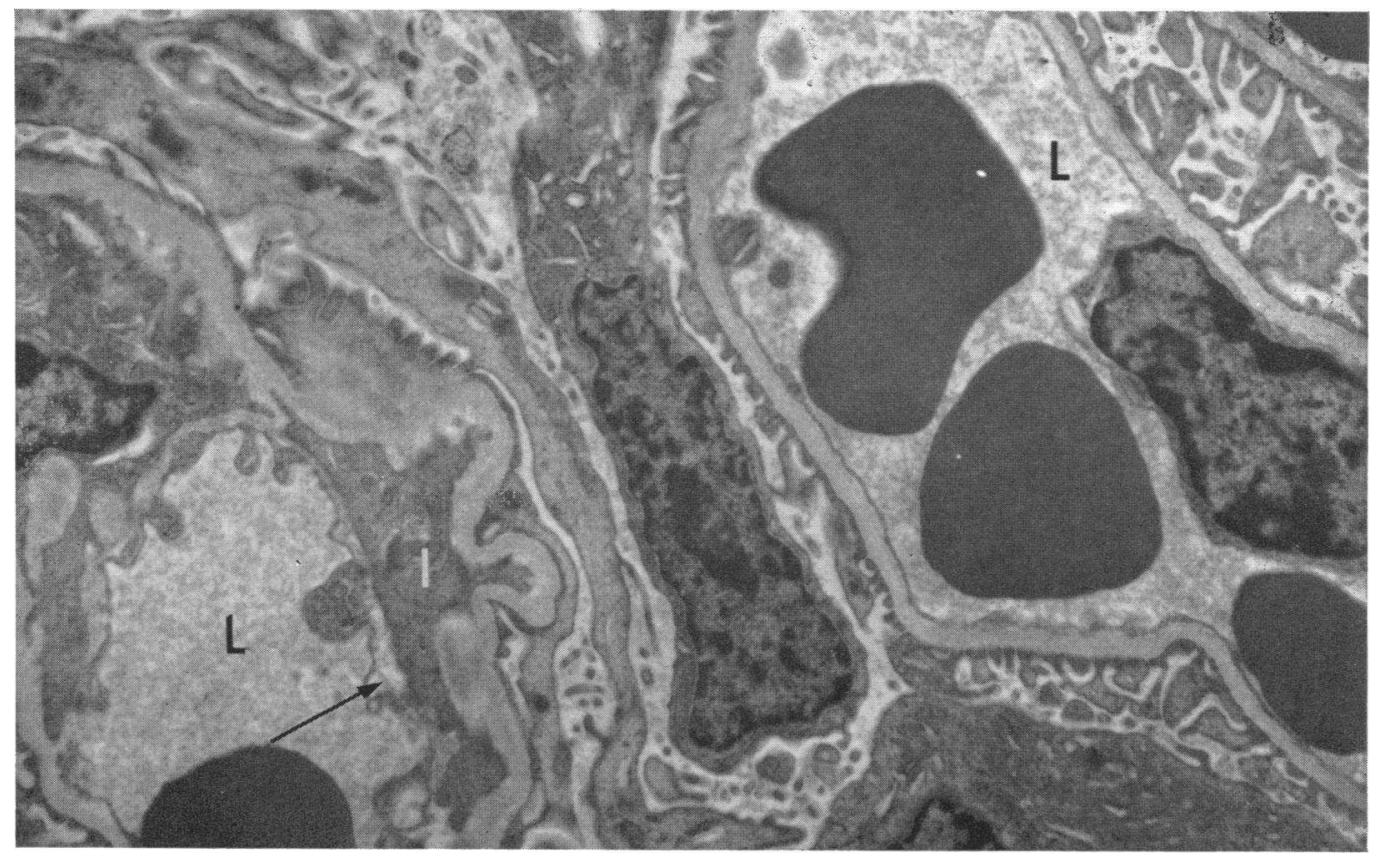

FIgURE 10 Toxemic sheep (group II). Sections of neighboring capillary loops of a glomerulus, showing virtually normal fine structure on the right, but reduplication of basement membrane (arrow) on the left, with intracapillary cell cytoplasm $(I)$ extending towards the periphery of the loop. $L$, capillary lumen. The abnormal loop on the left shows only focal fusion of epithelial foot processes. $\times 8000$.

species the glomeruli appear relatively bloodless, with occlusion of capillary lumina by swollen endothelial cells. Leukocytic infiltration is sparce in the glomeruli of preeclamptic women and was not seen in sheep in the present study.

The glomerular fine structural changes in toxemic sheep include swelling of endothelial cytoplasm, increase in size of mesangium, reduplication of basement membranes in peripheral parts of capillary loops giving them a mesangial-like appearance, and widespread fusion of epithelial foot processes together with microvillation of epithelial cytoplasm. These changes, although widespread and affecting all glomeruli, are not ubiquitous, for in practically every case, some peripheral capillary loops appear remarkably normal. These fine structural appearances are very similar to those seen in human toxemia (22).

The reversibility of the uremia in one animal after lambing is of interest; heretofore recovery has either not occurred or occurred only seldom after delivery. Since previous investigations of ovine toxemia have relied upon neurological signs as evidence of the disease, the failure to note recovery after delivery may be a reflection of the irreversibility of the process when neurological involvement is present. Similarly, previous studies have emphasized the neurological signs and hypo- glycemia in twin-bearing ewes, "twin lamb disease," and the finding of uremia and proteinuria not associated with neurological signs indicates that the incidence of ovine toxemia must be greater than previously recognized. The triad of twin lambs, prominent neurological signs, and hypoglycemia seems to have been misleading in excluding animals with azotemia but without neurological findings. It is conceivable that proteinuria and azotemia as sole manifestations of toxemia occur frequently in the pregnant ewe. The presence of proteinuria in five of six animals who did not develop other evidence of toxemia but who by light microscopy had minimal capillary obliteration and swelling of the glomeruli may be indicative of this and raises the question as to the role which undetected episodes of toxemia may have in the development of chronic renal disease reported in this species (23).

Whether the protein present in the initial urine examination represents a rapid induction of proteinuria by the stress of transportation is not clear. Urine from 10 nonpregnant ewes and three nonstressed pregnant ewes did not contain protein. Similarly, five toxemic animals and two animals of group III with pathologic changes of the glomeruli did not have proteinuria on the initial examination and developed it during the course of observation. Thus several animals developed proteinuria 
with toxemia and others may have developed it too soon after being stressed for a baseline urine to have been obtained.

Although it is possible that toxemia in sheep represents two diseases, one primarily a neurological one, the other manifesting renal signs, the finding of identical changes in the glomeruli of animals with and without neurological involvement makes a systemic disease with differing manifestations seem likely.

The presence of a glomerular lesion in the absence of hypertension suggests that mechanisms other than hypertension may be of importance in the renal changes of preeclampsia. Although by definition hypertension is an integral part of human preeclampsia, the actual role that hypertension plays in the clinical and pathological picture of preeclampsia is open to question. Hypertension would be an unlikely explanation for the glomerular changes found in human preeclampsia since they do not occur in other acute hypertensive states and even in the presence of proteinuria, azotemia, and convulsions, severe diastolic hypertension is not a distinctive finding in most cases of preeclampsia.

The cause of the striking rise in plasma renin activity in all toxemic animals is presumed to be renal ischemia. This rise in plasma renin contrasts with the decline in plasma renin (24), aldosterone excretion (25), and secretion (26) reported in preeclampsia. Thus the salt retention and edema of human preeclampsia seems primarily to be the result of factors other than increased aldosterone secretion, possibly the reduction in glomerular filtration rate which occurs. Since pregnant rabbits (27) suppress plasma renin activity with deoxycorticosterone acetate (DOCA) and a high salt diet and pregnant women reduce aldosterone secretion with salt loading (28), the reported changes in plasma renin activity with preeclampsia may be the result of extracellular fluid expansion and edema. No toxemic ewe developed edema but all animals in the study were deprived of salt and to some extent, salt depleted because of starvation. Whether edema, a decline in plasma renin, and conceivably hypertension would have occurred if the toxemic animals were given salt is unknown.

The decreased sensitivity to angiotensin is similar to other conditions associated with elevated plasma renin activity $(29,30)$ but contrasts with the increased sensitivity to angiotensin in human preeclampsia (31).

The absence of renin-like enzyme in both sheeep uterus and amniotic fluid contrasts with the high concentration of a renin like enzyme in rabbit and human uterus and amniotic fluid (32-34). Any role uterine renin plays in the hypertension of preeclampsia is speculative but the absence of renin in sheep uterus and amniotic fluid and the failure of hypertension to develop with a toxemia that otherwise has so many similarities to preeclampsia deserves further investigation.

Since there is evidence to suggest uterine ischemia as a cause of preeclampsia $(35,36)$ the question arises whether uterine blood flow was reduced by stress in these experiments. Catecholamines are known to decrease uterine blood flow in the pregnant ewe (37). The greater incidence of toxemia in twin-bearing ewes could then be related to greater ischemia developing when reductions in uterine blood flow occur in a situation known to be associated with an augmented blood requirement (38). Uterine ischemia might liberate a toxic substance which damages glomeruli and conceivably capillaries throughout the body. There was no evidence in this regard for release into the circulation of thromboplastic material with the resultant thrombotic process being the cause of the renal and CNS disease. Plasma fibrinogen levels did not fall, there was no evidence of a hemorrhagic diathesis clinically or at postmortem and fibrin deposits were not seen in the blood vessels of the organs examined histologically.

The cause of ovine toxemia has not been elucidated by this study. Clinically the motor weakness had the appearance of an acute polyneuropathy, although the stupor and convusions indicated brain involvement. The absence of pathological changes by light microscopy in brain and nerve has been noted by others ( 3 ) and either could be related to the acute nature of the process preventing the development of obvious changes or could reflect changes which are too subtle to be revealed by light microscopy. The findings of definite changes in glomeruli in preeclampsia went largely unrecognized until their fine structure was investigated. In future investigations of ovine toxemia the application of electron microscopy to the study of capillaries of the nervous system would appear to be warranted, since clinically the condition seemed most compatible with a widespread small vessel disease. If such a process is elicited by stress, toxemia of pregnancy in the ewe would be a unnique example of a psychosomatic disease.

\section{ACKNOWLEDGMENTS}

We are grateful for the technical assistance of W. C. B. Brown, Clifford Hanson, Barbara Moulton, and Mrs. Saideh Safavi and the staff at the Royal Agricultural Station, Compton England for their care of the animals during the course of this study.

This study was supported in part from grants from the National Institutes of Health, HE-09884 and HE-08729, and the Central Ohio Heart Association.

\section{REFERENCES}

1. Assali, N. S., L. D. Longo, and L. W. Holm. 1960. Toxemia-like syndromes in animals. Obstet. Gynecol. 15: 151. 
2. Fraser, A. H. H., W. Godden, L. C. Snook, and W. Thomson. 1939. Ketonaemia in pregnant ewes and its possible relation to pregnancy disease. J. Physiol. (London). 97: 120 .

3. Parry, H. B. 1950. Toxemia of pregnancy in the domestic animals, with particular reference to the sheep. Ciba Foundation. Toxemias of pregnancy: human and veterinary. J. \& A. Churchill Ltd., London.

4. Reid, R. L. 1958. Pregnancy toxaemia in sheep. Agriculture London. 4(2): 20.

5. Goldblatt, H., J. R. Kahn, and H. A. Lewis. 1943. Studies on experimental hypertension. J. Exp. Med. 77: 297.

6. Holm, L. W., Y. J. Katz, H. R. Parker, L. C. Chesley, and N. S. Assali. 1960. Experimental hypertension in pregnant sheep. Amer. J. Physiol. 199: 633.

7. Baron, D. N., and J. L. Bell. 1957. A simple specific titration method for serum calcium. Clin. Chem. Acta. 2: 327 .

8. Nilsson, I. M., and B. Olow. 1962. Determination of fibrinogen and fibrinogenolytic activity. Thromb. Diath. Haemorrh. 8: 297.

9. Ryan, J. W., J. K. McKenzie, and M. R. Lee. 1966. A simple, rapid method for the quantitative assay of plasma renin. Abstracts of the 3rd International Congress of Nephrology, Washington, D. C. 265. (Abstr.)

10. Pickering, G. W., M. Prinzmetal, and A. R. Kelsall. 1942. The assay of renin in rabbits with experimental renal hypertension. Clin. Sci. 4: 401.

11. Haas, E., and H. Goldblatt. 1963. Studies on renin. Biochem. Z. 338: 164.

12. Sparling, C. M., G. A. Mook, J. Nieveen, L. B. Van der Slikke, and W. C. Zijlstra. 1960. Calibration of dye dilution curves for calculating cardiac ouput and central blood volume. Excerpta Med. Int. Congr. Ser. 30. Rome. 595.

13. Emanuel, R., J. Hamer, Bi-nin Chiang, J. Norman, and J. Manders. 1966. A dynamic method for the calibration of dye dilution curves in a physiological system. Brit. Heart J. 28: 143.

14. Kingsley, G. R. 1942. Direct biuret method for the determination of serum protein as applied to photoelectric and visual colorimetry. J. Lab. Clin. Med. 27: 840.

15. Huckabee, W. E. 1961. Abnormal resting blood lactate. I. The significance of hyperlactemia in hospitalized patients. Amer. J. Med. 30: 833 .

16. Reid, R. L. 1960. Studies on the carbohydrate metabolism of sheep. XII. Further studies on the diabetic nature of the metabolic abnormalities in ovine pregnancy toxemia. Aust. J. Agr. Res. 11: 530.

17. Assali, N. S., L. Holm, and D. L. Hutchison. 1958. Renal hemodynamics, electrolyte excretion and water metabolism in pregnant sheep before and after the induction of toxemia of pregnancy. Circ. Res. 6: 468.

18. Arky, R. A., and N. Freinkel. 1964. Alcohol hypoglycemia. Effects of ethanol on plasma. Arch. Intern. Med. 114: 501 .

19. Baird, D., and J. S. Dunn. 1933. Renal lesions in eclampsia and nephritis of pregnancy. J. Pathol. Bacteriol. $37: 291$.
20. Altchek, A. 1961. Electron microscopy of renal biopsies in toxemia of pregnancy. J. Amer. Med. Ass. 175: 791.

21. Pollak, V. E., and J. B. Nettles. 1960. The kidney in toxemia of pregnancy: a clinical and pathologic study based on renal biopsies. Medicine. 39: 469.

22. Pirani, C. L., and V. E. Pollak. 1968. Renal involvement in toxemia of pregnancy. In Structural Basis of Renal Disease. E. L. Becker, editor. Harper and Row Publishers Inc., New York. 401.

23. Lerner, R. A., and F. J. Dixon. 1966. Spontaneous glomerulonephritis in sheep. Lab. Invest. 15: 1279.

24. Brown, J. J., D. L. Davies, P. B. Doak, A. F. Lever, J. I. S. Robertson, and P. Trust. 1965. Plasma renin concentration in hypertensive disease of pregnancy. Lancet. 2: 1219.

25. Kumar, D., L. A. W. Feltham, and A. G. Gornall. 1959. Aldosterone excretion and tissue electrolyte in normal pregnancy and preeclampsia. Lancet. 1: 541.

26. Watanabe, M., C. I. Meeker, M. J. Gray, E. A. H. Sims, and S. Solomon. 1965. Aldosterone secretion rates in abnormal pregnancy. J. Clin. Endocrinol. 25: 1665.

27. Gorden, P., T. F. Ferris, and P. J. Mulrow. 1967. Rabbit uterus as a possible site of renin synthesis. Amer. J. Physiol. 212: 703 .

28. Watanabe, M., C. I. Meeker, M. J. Gray, E. A. H. Sims, and S. Solomon. 1963. Secretion rate of aldosterone in normal pregnancy. J. Clin. Invest. 42: 1619.

29. Laragh, J. H. 1962. Interrelationships between angiotensin, norepinephrine, epinephrine, aldosterone secretion, and electrolyte metabolism in man. Circulation. 25: 203.

30. Kaplan, N. M., and J. G. Silah. 19644. The angiotensininfusion test. A new approach to the differential diagnosis of renovascular hypertension. N. Engl. J. Med. $271: 536$.

31. Chesley, L. C. 1965. Renal function in pregnancy. Bull. N. Y. Acad. Med. 41: 811 .

32. Ferris, T. F., P. Gorden, and P. J. Mulrow. 1967. Rabbit uterus as a source of renin. Amer. J. Physiol. 212: 698.

33. Gorden, P., T. F. Ferris, and P. J. Mulrow. 1966 Studies of uterine renin. J. Clin. Invest. 45: 1015.

34. Brown, J. J., D. L. Davies, P. B. Doak, A. F. Lever, and J. I. S. Robertson. 1964. The presence of renin in human amniotic fluid. Lancet. 2: 64.

35. Ogden, E., G. J. Hildebrand, and E. W. Page. 1940. Rise of blood pressure during ischemia of gravid uterus. Proc. Soc. Exp. Biol. Med. 43: 49.

36. Hodari, A. A. 1967. Chronic uterine ischemia and reversible experimental "toxemia of pregnancy." Amer. J. Obstet. Gynecol. $97: 597$.

37. Assali, N. S., L. W. Holm, and N. Sehgal. 1962. Regional blood flow and vascular resistance of the fetus in utero. Action of vasoactive drugs. Amer. J. Obstet. Gynecol. 83: 809.

38. Metcalfe, J., S. L. Romney, L. H. Ramsey, D. E. Reid, and C. S. Burwell. 1955. Estimation of uterine blood flow in normal human pregnancy at term. J. Clin. Invest. 34: 1632 . 